Dlouhy J., Grobler W., Binninger M., and Haghsheno S. (2017). "Lean Equipment Installation - Potentials of Using Takt Planning." In: LC3 2017 Volume II - Proceedings of the 25th Annual Conference of the International Group for Lean Construction (IGLC), Walsh, K., Sacks, R., Brilakis, I. (eds.), Heraklion, Greece, pp. 721-728. DOI: https://doi.org/10.24928/2017/0091

\title{
LEAN EQUIPMENT INSTALLATION - POTENTIALS OF USING TAKT PLANNING
}

\author{
Janosch Dlouhy ${ }^{1}$, Willem Grobler ${ }^{2}$, Marco Binninger ${ }^{3}$, and Shervin Haghsheno ${ }^{4}$
}

One of the major OEMs (Original Equipment Manufacture - Car Manufacture) in the automotive industry has successfully implemented Takt planning in several of their plant construction projects. This has allowed them to do quicker handovers as well as the possibility to do partial handovers. The efficiency and transparency of this process can even be further improved when the installation of production equipment follows the same method, this enables the OEM to reduce the overall time required for the project delivery. This paper shows the advantages of using Takt Planning in the equipment installation phase. A case-study shows the first experience using Takt Planning and the existing connections to the building construction site. This paper is focused on Takt planning and highlights the potentials of lean equipment installation as well as showing the first results of an implemented real case.

Keywords: Takt Planning, Production System, Equipment installation, production, client.

\section{INTRODUCTION}

Takt Planning is a Lean Construction method which is used in construction projects for organizing the construction site. It is a takt time and takt area based method (Haghsheno 2016) for the realization phase of construction projects. In recent years, several papers have looked at Takt Planning in construction (Frandson et al. 2013) (Frandson et al. 2014) (Faloughi et al. 2015) (Frandson \& Tommelein 2016), nevertheless no work has looked into the use of this methodology for equipment installation. Takt Planning and Takt Control as a method within the research field of Lean Construction was successfully implemented in several plant constructions of a major OEM in the automotive sector. This carmanufacture started the Takt Planning approach within first construction projects by enabling and training construction companies.

The Results in these projects show a stable and continuous workflow on site leaded by the Takt time with high transparency of achieved goals. This more efficient way of building, and the possibility of planned partial handovers show the time potentials in the end of a construction project by using buffers. While there is no need to use these buffers by the general contractors, these time potentials could be used by the equipment installation of the production line.

After the successful and early handover to the equipment installation in this project, potentials in building the production line has been seen in using the same methodology for the installation of the equipment. In the third lighthouse project the company implements the three level model in Takt Planning and Takt Control (Dlouhy et al. 2016)

Research Fellow, Karlsruher Institute of Technology, Germany, janosch.dlouhy@kit.edu Project Leader Equipment Insallation, BMW AG, willem.grobler@bmw.de

Research Fellow, Karlsruher Institute of Technology, Germany, marco.binninger@kit.edu

Professor, Karlsruher Institute of Technology, Germany, shervin.haghsheno@kit.edu 
with their general contractors (SE Partner) for the installation of the production line. These next step is part of the value chain for delivering the value of the costumer. Detailed needs and dependencies are shown by using the same method.

So, the question of this research is: could the Takt planning approach for installation of equipment be used and what are the effects? Are the results and potentials like transparent time buffers verifiable in installation for equipment?

\section{DEFINITIONS AND FOUNDATIONS}

In the presented example, the method of Takt Planning and Takt Control (Haghsheno et al., 2016) is used in the system of the Three Level Model (Dlouhy et al., 2016). Haghsheno et al. (2016) describe a prophase before the Takt Planning called process analysis in which the project is structured and the sequence of trades is defined. In this phase, the customer has the biggest influence on the project and its outcome. Within this phase, the client defines the areas with high priority and the handover accordingly. Afterwards in the Takt Planning phase, the calculation of the Takt area depending on different performance factors of trades is done. The performance factors are based on each working step. The working steps are clustered to work packages and afterwards accumulated into waggons of the train. Also, the leveling of work packages is important for the efficiency of the system (Binninger et al., 2016). These theories are adapted to the needs of the equipment project team. Therefore, the terms and goals are different to major construction sites.

The Takt Control for equipment project team uses the same Takt Control boards as the construction team. This leads to more transparency and understanding between the different phases.

\subsection{Definition of Lean Equipment}

Why is Lean Equipment part of Lean Construction? Lean Construction is the adaption of the Lean Principles named by Womack, J. \& Jones, D. (1996) to construction. They analyzed production processes of the Toyota Production System. But until now the building of production lines was not part of the methodic approach in production.

Construction processes are using different or modified methods to implement Lean principles like Last Planner System, Location Based Planning System or Takt Planning and Takt Control. In production, the product is flowing and value adding process by machines and workers are immobile. In construction, the products are immobile and the value adding process by machines and workers is flowing. Keitel (2008 p. 3) describes construction and equipment installation (plant construction) as a "transient single piece production".

\subsection{Different Types of Projects}

- Greenfield Project - Building of a new "State of the Art" production line

- Brownfield Project - Building a new production line in an existing production environment.

- Blackfield Project - Building some parts of the production line in shut down time of production 


\subsection{Challenges in the normal Equipment Process}

It is common in equipment installation to have more than one general contractor (SEPartner). Three and more contractors are usual to bigger plant projects. The total number of subcontractors could be up to more than 150. These companies are normally not connected to each other nor are they aligning their time and work planning. Dependencies between each of them are given by interfaces in the production line and the amount of work. Space for transportation and storing is lacking.

- Transparency for solving interface problems by the team is impossible in single team scheduling.

- Bottlenecks in time and laydown areas or material are not seen before. Steering the workflow and controlling the quality of work is getting more complicated and harder day by day.

- Structured coordination between SE-Partners during the realization is very hard to align.

\subsection{Status quo in the Installation Process}

The equipment installation of highly automated production lines is, when regarding one robot, repetitive work. In a body shop, a robot station could be including two equal robots and infrastructure. In a production line, there are between 100 and 300 stations. That means 200 to 600 robots are part of the equipment installation.

Workers in the installation are well educated and specialized. The use and coordination of the rare experts and their knowledge is getting more important to save expensive labor hours and time in the construction process.

\section{THE REAL CASE STUdy PROJECT}

\subsection{Research Method}

The research method is focusing on a real case study. The implementation of the Takt Planning method was driven by the client. He and his Lean Construction team used the same method, strategy for implementation and training like they did for construction projects:

- Short introduction (1hour) to the SE-Partner by the Clients Project leader.

- First Workshop (2 days) with all SE-Partners, client project team, Lean Construction Experts. First day: Lean Simulation and teaching the three level model. Second day: Training Takt Control and Start Takt Planning for the project. Definition the interfaces between Construction and Equipment Team.

- First Takt Planning for every SE Partner (contractor) internally

- Link the 3 different schedules together in one master schedule.

- Align these schedules with all parties.

- Cycled adaption of the Takt schedule.

The potentials and results are in the stage of pre-realization planning. Therfore this research paper is based on the estimated and planned effects of applying the three-level method. The realization must be analyzed separately. 


\subsection{Project Description}

The relevant car-manufacture made a very late decision to change the product line for one of their older well established production facilities. The change in product was severe, and especially in the Body-in-White (BIW - a special Body Shop) production facility the changes were massive. The BIW process is the first major step of three that makes up the manufacturing of a car. During this step steel, aluminum and in special cases carbon fiber are joined together to form the structure or skeleton of the car. Joining is done by automated robots. For this specific project a normal Brownfield project was not an option due to the short timeline as well as the complex changes required to the existing production lines.

A Greenfield project was decided for the new BIW production facility. The late project change decision caused the project to be immediately one year behind the reference schedule. A BIW project is comprised of two major phases, the design phase and the realization phase. Both phases require about 18 months for execution, spanning a total of three years. For the relevant project, only 24 months were left. Catch up during the design phase was done by a copy and paste method from a similar product line to speed up the process in the design phase. The problem area and the focus of this paper is the equipment installation phase.

The equipment installation phase for a BIW project consist of three major sub-phases. These sub-phases are the mechanical installation phase, the electrical installation phase and the commissioning phase.

- During the mechanical installation, sub-phase all production hardware is installed and mounted. The hardware includes robots, welding equipment, welding fixtures and material handling equipment. This sub-phase is scheduled to be 4 months long.

- During the electrical installation, sub-phase all production hardware and equipment are electrically installed by connecting all the relevant power and communication cables. This sub-phase is also scheduled to be 4 months long.

- The final sub-phase is commissioning. This sub-phase is considered the most important and most value-adding phase of the three sub-phase. During this time, all Programmable Logic Controllers (PLCs) and robots are programmed to autonomously operate the production facility. This sub-phase is scheduled to be 10 months long and is the least flexible phase in terms of optimization.

One chance to reduce the overall realization phase is to optimize the mechanical and electrical installation sub-phases, this iswhere lean equipment comes into consideration.

The BIW project was awarded to four different SE Partners, each responsible to complete a different section of BIW production facility, including both the design and realization phases. A SE Partner is a production line design and build company that assist OEMs with project realization. The work content was split as follows:

- SE Partner A was responsible for all the smaller strategic sub-assemblies,

- SE Partner B was responsible for the main lines that brings the sub-assemblies to the main car body,

- SE Partner C was responsible for all the material handling systems, and

- SE Partner D was responsible for the final line where hang-on-parts like doors are fitted. 
The work content split caused several interfaces between the four SE Partners. This means that a SE Partner is not only dependent on himself, but they also depend on the working schedule and completion of each other.

In the equipment installation phase, there is normally not much attention given to interfaces between contractors. It is expected that the SE Partners will have casual interaction between each other and follow a relaxed installation approach method, working around the problems of each other. When the timeline is significantly reduced, like it is with this reference project, there is no chance to do this anymore.

The situation and the project face two major problems:

- Problem 1 was that there is currently no way to optimize the mechanical and electrical installation sub-phases significantly so that more time can be allocated for the commissioning sub-phase.

- Problem 2 was that there is no efficient method in BIW planning to synchronize the installation activities between the four SE Partners.

Assuming the results will be similar, it is predicted that the mechanical and electrical subphases can be significantly reduced as well as complexity for interfaces between the SE Partners decreased. The following part of the paper, document the Project preparation.

\subsection{Case Study Result}

The results shown in figure 1 and 2 are done in the first 3 steps of the implementation. So, every SE-Partner did the first Takt Planning for himself. Then the Takt schedules were connected and aligned. As figure 1 demonstrates, the Takt Planning was used in 5 steps:

1. List all activities and state their duration.

2. Divide layout into smaller workable sections.

3. Calculate the days per activity and area.

4. Divide activities into daily tasks and color code.

5. Populate timing plan with a Takt schedule.

6. Align the Takt schedule with all others SE-Partners (not in figure 1)

\begin{tabular}{|c|c|c|c|c|c|}
\hline \multicolumn{2}{|l|}{ Step 1} & \multirow{2}{*}{$\begin{array}{l}\text { Step } 2 \\
\text { Areas }\end{array}$} & \multirow{2}{*}{\begin{tabular}{|c|} 
Step 3 \\
$\mathrm{DAA}^{2}$ \\
\end{tabular}} & \multicolumn{2}{|r|}{ Step 4} \\
\hline Activities & Days & & & Calc. & Takt \\
\hline Mount robot risers & 5 & 5 & 1 & 1 & w1 \\
\hline Install robots & 9 & 5 & 1.8 & 2 & $W_{2}, W_{3}$ \\
\hline Instal RPS & 10 & 5 & 2 & 2 & W4,W5 \\
\hline Install HIPS & 1 & 5 & 0.2 & 0.5 & Wo \\
\hline Install KOKATS & 2 & 5 & 0.4 & 0.5 & Wô \\
\hline Mechanicad installation and leveling fixures & 20 & 5 & 4 & 4 & W7,W8,W9,W10 \\
\hline Install part tables & 20 & 5 & 4 & 4 & $\mathrm{~W} 11, \mathrm{~W} 12, \mathrm{~W} 13, \mathrm{~W} 14$ \\
\hline Install purchase parts & 20 & 5 & 4 & 4 & W15,W16,W17,W18 \\
\hline Instal stationary Weld guns & 2 & 5 & 0.4 & 1 & W19 \\
\hline Install glue equipment & 5 & 5 & 1 & 1 & $w_{20}$ \\
\hline Instal visions systems & 5 & 5 & 1 & 1 & W21 \\
\hline Install PHW & 15 & 5 & 3 & 2 & W22, W23, W24 \\
\hline Safety Fence & 15 & 5 & 3 & 2 & W25, W26, W27 \\
\hline Sefety doors & 20 & 5 & 4 & 4 & $\mathrm{~W}_{28,} \mathrm{~W}_{29}, \mathrm{~W}_{3} 0, \mathrm{~W}_{3} 1$ \\
\hline Dockings & 2 & 5 & 0.4 & 0.4 & W32 \\
\hline Weld guns & 3 & 5 & 0.6 & 0.6 & W32 \\
\hline Gippers & 4 & 5 & 0.8 & 1 & W33 \\
\hline
\end{tabular}

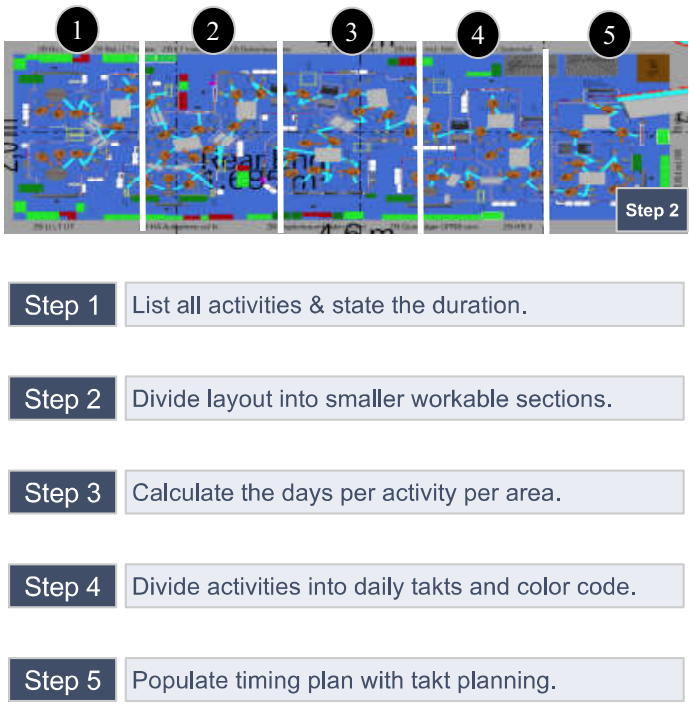

Figure 1: Steps 1 - 5 of Takt Planning in Lean Equipment Installation 
The result showed in figure 2 is a single potential of one general contractor. The interfaces are not included. But the basic time line was as well just a single source time schedule in which no connection to other parties was integrated.

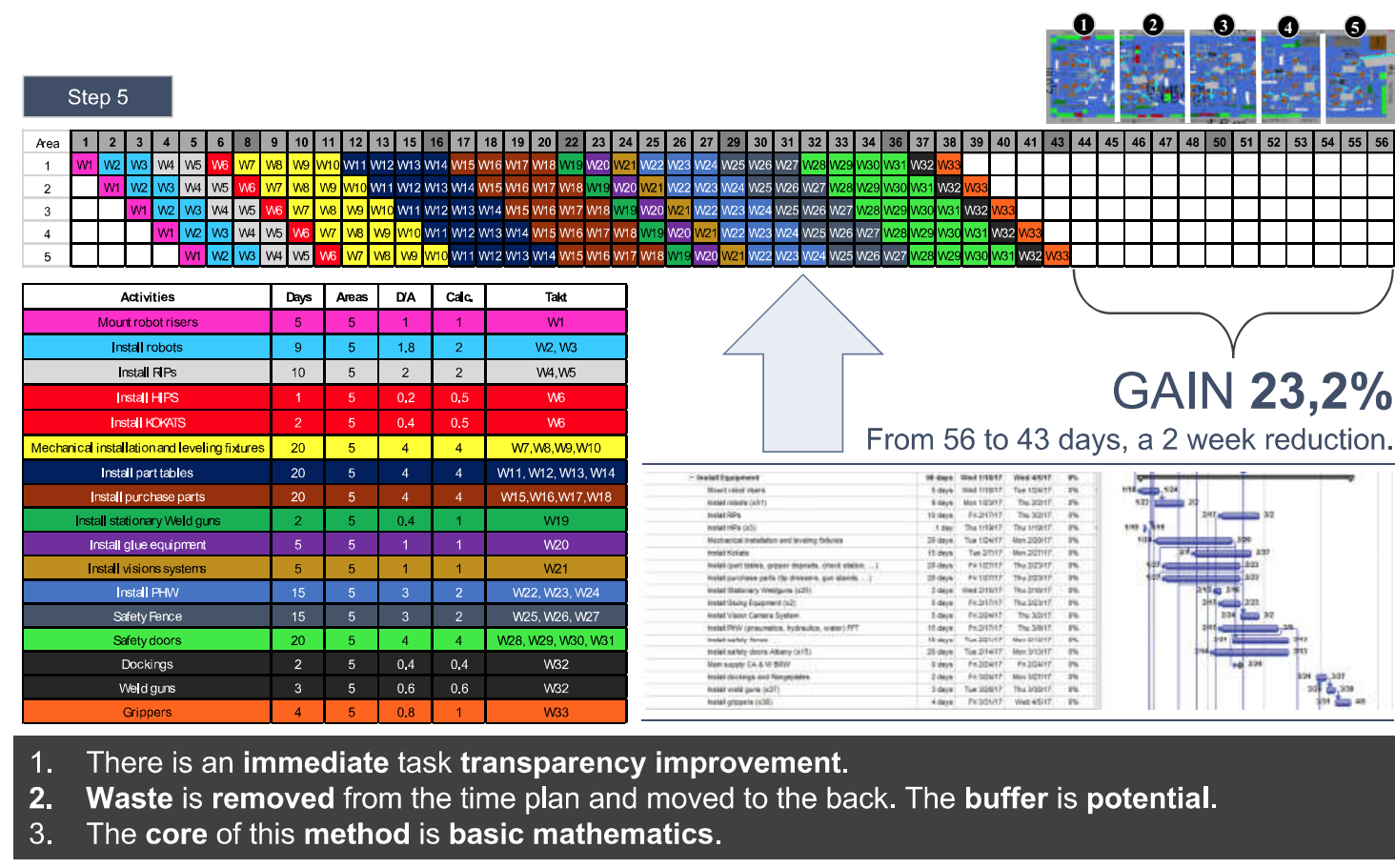

Figure 2: Example of the results by one contractor

The potential of $23,2 \%$ of the total installation time of one specific contractor could be used for delays, interfaces and an early start of commissioning like shown in figure 3 .

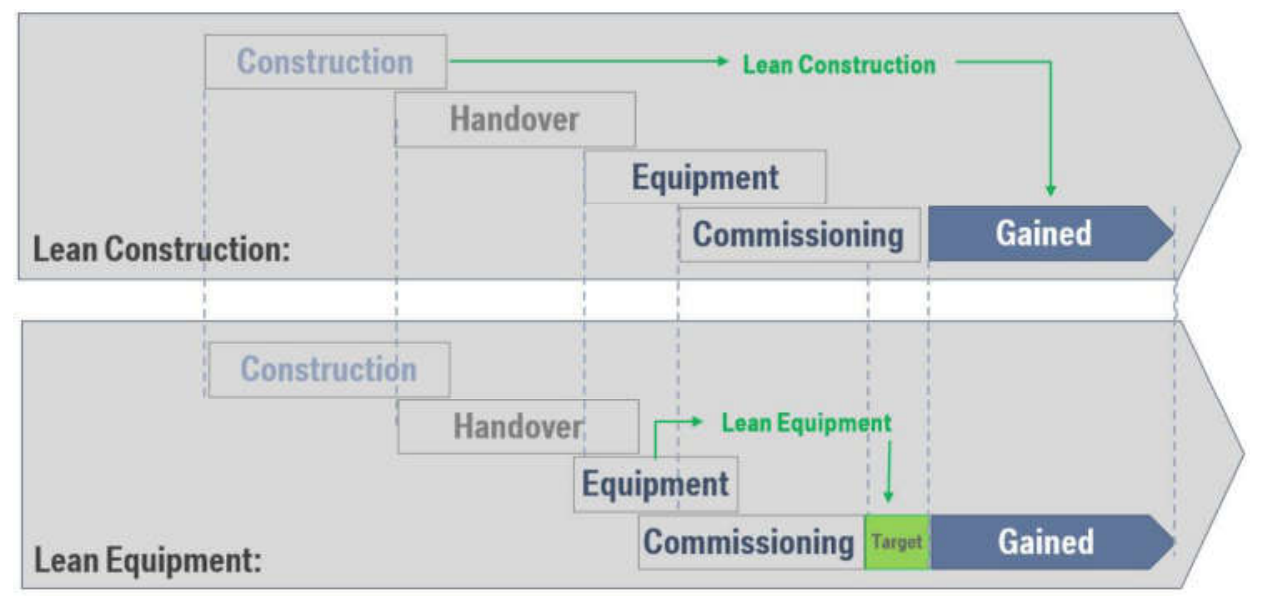

Figure 3: Realization phases comparing Lean Construction and Lean Equipment Installation.

The problems mentioned in chapter 3.1. are answered by the results of the case study:

1. There is a methodical way to optimize time in equipment installation.

2. The transparent and location based time schedule gives all contractors the possibility to verify their time scheduling with the overall project. 
But there are more soft advantages coming with this approach. The Takt schedule is a kind of communication interface to identify early collisions and bottlenecks between contractors. That enables a common understanding of the project's possibilities and challenges. While the Takt schedule is departed in short Takts, it is easy to track and control a lot of works. Therefore, shorter feedback loops give the possibility to react quicker. This collaboration has the chance to grow, with a higher level of communication and transparency.

\section{DisCUSSION AND CONCLUSION}

As mentioned in this paper, the results are estimated and planned and not yet realized. The equipment installation is still in process. The theoretical potentials should be proven in various projects. But the method shows equal potentials and gives the opportunity for time savings in insatllation projects like in this installation of a production line. The realized time saving needs to be quantified by the Takt Control of the project. This should be documented and analyzed to get specific data and KPIs for Takt Planning and Takt Control in equipment installation.

The discussion, if contracts for further projects include aspects and services for Takt Planning and Takt Control.

In fact, the method should be implemented in projects even earlier then the realization phase. Even in the planning phase, information and data out of Takt Planning could be very important.

The mayor results are equal to the potentials of Takt Planning in construction. The method is useable in a similar way in equipment installation. So, time buffers are verifiable in installation for equipment. For the clients value a transparent value stream from construction over equipment installation to the start of production shows a lot of potentials in reducing variances, reducing interphases, increasing flow and making transparent value adding decisions.

\section{REFERENCES}

Binninger, M., Dlouhy, J., Oprach, S. \& Haghsheno, S. (2016), Methods for Production Leveling - Transfer from Lean Production to Lean Construction In: 24th Annual Conference of the International Group for Lean Construction. Boston, USA, 20-22 Jul 2016.

Dlouhy, J., Binninger, M., Oprach, S. \& Haghsheno, S. (2016), Three-Level Method of Takt Planning and Takt Control - a New Approach for Designing Production Systems in Construction In: 24th Annual Conference of the International Group for Lean Construction. Boston, USA, 20-22 Jul 2016.

Faloughi, M., Bechara W., Chamoun J., \& Hamzeh F. 2015. WIP Design in a Construction Project Using Takt Time Planning. In 23rd Annual Conference of the International Group for Lean Construction. 163-172.

Frandson, Adam, Berghede, Klas \& Tommelein, Iris D. 2013. Takt Time Planning for Construction of Exterior Cladding. In 21th Annual Conference of the International Group for Lean Construction. 527-536. 
Frandson, Adam, Berghede, Klas \& Tommelein, Iris D. 2014. Takt-Time Planning and the Last Planner. In 22nd Annual Conference of the International Group for Lean Construction. Oslo, Norway, 571-580.

Frandson, Adam \& Tommelein, Iris D. 2016. Takt Time Planning of Interiors on a PreCast Hospital Project. In 24th Annual Conference of the International Group for Lean Construction. http://iglc.net/Papers/Details/1339.

Haghsheno, S., Binninger, M., Dlouhy, J. \& Sterlike, S. (2016): History and Theoretical Foundations of Takt Planning and Takt Control In:, 24th Annual Conference of the International Group for Lean Construction. Boston, USA, 20-22 Jul 2016.

Keitel, T. (2008): Factoring als Instrument des Risikomanagements im Projektgeschäft. Gabler Verlag/GWV Fachverlage GmbH, Wiesbaden.

Koskela, L. (1992): Application of the New Production Philosophy to Construction. Technical Report \# 72, Center for Integrated Facility Engineering, Department of Civil Engineering, Stanford University, USA.

Womack, J. \& Jones, D. (1996): Lean Thinking: Banish Waste and Create Wealth in your organization, Simon \& Schuster. 